\title{
A phase II study of FOLFIRI-3 (double infusion of irinotecan combined with LV5FU) after FOLFOX in advanced colorectal cancer patients
}

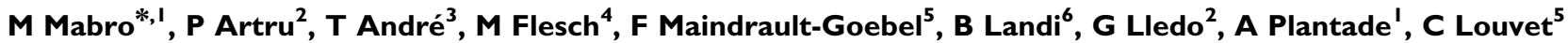 and A de Gramont ${ }^{5}$ on behalf of GERCOR}

'Department of Medical Oncology, Hôpital Foch, 40 rue Worth, 92151 Suresnes Cedex, France; '²Department of Medical Oncology, Clinique Saint-Jean, Lyon, France; ${ }^{3}$ Department of Medical Oncology, Hôpital Tenon, Paris, France; ${ }^{4}$ Department of Medicine, Hôpital de Dijon, Dijon, France; ${ }^{5}$ Department of Medical Oncology, Hôpital Saint-Antoine, Paris, France; ${ }^{6}$ Department of Medical Oncology, Hôpital Européen Georges Pompidou, Paris, France

In advanced colorectal cancer previously treated with oxaliplatin, efficacy of irinotecan-based chemotherapy is poor and the best regimen is not defined. We designed FOLFIRI-3 and conducted a phase II study to establish its efficacy and safety in advanced colorectal cancer patients previously treated with FOLFOX. FOLFIRI-3 consisted of irinotecan $100 \mathrm{mg} \mathrm{m}^{-2}$ as a 60 -min infusion on day I, running concurrently with leucovorin $200 \mathrm{mg} \mathrm{m}^{-2}$ as a 2 -h infusion on day I, followed by 46-h continuous infusion of 5-fluorouracil (5FU) $2000 \mathrm{mg} \mathrm{m}^{-2}$, and irinotecan $100 \mathrm{mg} \mathrm{m}^{-2}$ repeated on day 3, at the end of the 5FU infusion, every 2 weeks. Sixty-five patients entered the study. The intent-to-treat objective response rate was $23 \%(95 \% \mathrm{Cl} \mid 3-33 \%)$. Disease was stable in $37 \%$ of patients, progressed in $26 \%$ and was not assessable in $14 \%$. From the start of FOLFIRI-3, median progression-free survival was 4.7 months and median survival 10.5 months. Main toxicities (\% of patients) were grade 3-4 diarrhoea $23 \%$ and grade 4 neutropenia I I\%. FOLFIRI-3 is a promising regimen achieving high response rate and progression-free survival in patients previously treated with FOLFOX with a moderate toxicity.

British Journal of Cancer (2006) 94, 1287-1292. doi:I0.1038/sj.bjc.6603095 www.bjcancer.com

Published online II April 2006

(c) 2006 Cancer Research UK

Keywords: colorectal cancer; combination chemotherapy; irinotecan; 5-fluorouracil; leucovorin; phase II study

Colorectal cancer is the one of the commonest cancers worldwide and remains a leading cause of mortality. For many years the main treatment for metastatic colorectal cancer consisted of 5-fluorouracil (5FU) modulated by leucovorin (LV). Since 1990, tremendous progresses have been made through the availability of several new drugs, such as oxaliplatin and irinotecan (Cunningham et al, 1998; Rougier et al, 1998; De Gramont et al, 2000; Douillard et al, 2000; Saltz et al, 2000; Grothey et al, 2002; Goldberg et al, 2004).

Irinotecan has definite activity against advanced metastatic colorectal cancer both in chemotherapy-naive patients and after 5FU failure (Cunningham et al, 1998; Rougier et al, 1998; Douillard et al, 2000; Saltz et al, 2000). Two randomised studies in patients with 5FU bolus-resistant metastatic colorectal cancer established the superiority of irinotecan over best supportive care (Cunningham et al, 1998) or 5FU continuous-infusion regimens (Rougier et al, 1998). Later, two large multicentre randomised studies established the superiority of irinotecan combined with 5FU and LV over $5 \mathrm{FU}-\mathrm{LV}$ as first-line treatment of metastatic colorectal cancer (Douillard et al, 2000; Saltz et al, 2000). Two additional randomised studies demonstrated the superiority of oxaliplatin combined with LV5FU2 (FOLFOX4) over 5FU and LV as front

*Correspondence: Dr M Mabro; E-mail: m.mabro@hopital-foch.org Received 9 November 2005; revised 13 March 2006; accepted 13 March 2006; published online II April 2006 therapy (De Gramont et al, 2000; Grothey et al, 2002). More recently, in a large phase III study, FOLFOX4 achieved better response rate, progression-free survival and overall survival than the irinotecan-based IFL regimen as first-line treatment of metastatic colorectal cancer (Goldberg et al, 2004). However, few data are available about irinotecan-based chemotherapy in patients previously treated with FOLFOX. Thus, the FOLFIRI regimen achieved a $5 \%$ response rate in pretreated patients (André et al, 1999; Tournigand et al, 2004).

In vitro studies suggested that the synergy between irinotecan and $5 \mathrm{FU}$ is sequence dependent, with a higher cytotoxicity when irinotecan is administered before 5FU (Guichard et al, 1997; Mullany et al, 1998; Mans et al, 1999). Clinical data are less documented. In a phase II randomised study evaluating the sequence effect of irinotecan and 5FU, toxicities were affected by the sequence of administration, with a worsened tolerability when $5 \mathrm{FU}$ was followed by irinotecan (Falcone et al, 2001). These results suggested that cytotoxicity is higher when irinotecan is administered after 5FU (Falcone et al, 2001). Thus, we previously designed the FOLFIRI-2 regimen consisting of irinotecan $180 \mathrm{mg} \mathrm{m}^{-2}$ combined with a simplified LV5FU regimen, with irinotecan administered at the end of the 5FU infusion (Mabro et al, 2003). In this phase II study of patients with heavily pretreated colorectal cancer, efficacy was encouraging, with a $17 \%$ confirmed response rate and 4.1 months progression-free survival, but toxicity was high. 
Thus, irinotecan-based chemotherapy after FOLFOX needs to be improved and the best schedule is not yet established. We designed a new regimen, FOLFIRI-3, in which irinotecan is administered as two infusions: half-dose before 5FU and half-dose at the end of the 5FU infusion, and conducted this multicentre phase II study to evaluate the efficacy of the FOLFIRI-3 regimen in advanced colorectal cancer patients previously treated with FOLFOX regimen.

\section{PATIENTS AND METHODS}

This study was an open multicentre phase II study conducted from June 2001 to December 2002. The study fulfilled the Clinical Good Practice Guidelines and was approved by the Ethics Committee of La Pitié - Salpêtrière Hospital, Paris, France. Written informed consent was obtained from all patients prior to study entry.

The main end point of the study was progression-free survival. The other study parameters were: response rate, overall survival and toxicity.

\section{Inclusion criteria}

Patients were required to be $18-80$ years old, and to have metastatic adenocarcinoma of the colon or the rectum histologi- cally proven and previously treated with a FOLFOX regimen. An interval of at least 2 weeks must have elapsed since prior treatment. Other eligibility criteria were: no central nervous system metastases, WHO performance status $0-2$, initial evaluation $\leqslant 2$ weeks before inclusion by computed tomography scan prior to initiation of therapy and feasibility of regular follow-up. Required laboratory parameters included: neutrophil count $\geqslant 1500 \mu \mathrm{l}^{-1}$, platelet count $\geqslant 100000 \mu \mathrm{l}^{-1}$, serum alkaline phosphatase $<3$ times the upper limit of normal (ULN) and bilirubin $<1.5$ times ULN.

\section{Treatment administration}

FOLFIRI-3 regimen was given every 14 days as follows: on day 1 , irinotecan $100 \mathrm{mg} \mathrm{m}^{-2}$ as a 1 -h infusion, running concurrently with LV $200 \mathrm{mg} \mathrm{m}^{-2}$ as a 2 -h infusion via a Y-connector, followed by $5 \mathrm{FU} 2000 \mathrm{mg} \mathrm{m}^{-2}$ as a $46-\mathrm{h}$ infusion using a disposable elastomeric pump. On day 3, irinotecan $100 \mathrm{mg} \mathrm{m}^{-2}$ as a 1 -h infusion was repeated, at the end of the $5 \mathrm{FU}$ infusion (Figure 1). In the absence of grade 2 toxicity after two cycles, the dose of irinotecan was to be increased from 100 to $120 \mathrm{mg} \mathrm{m}^{-2}$ at days 1 and 3. Treatment was continued until disease progression or limiting toxicity.

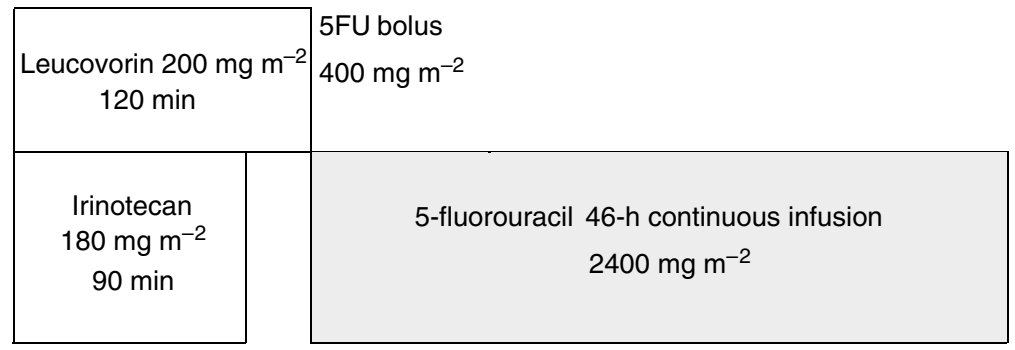

FOLFIRI: Irinotecan day 1 followed by bolus $5 \mathrm{FU}$ and 46 -h continuous $5 \mathrm{FU}$.

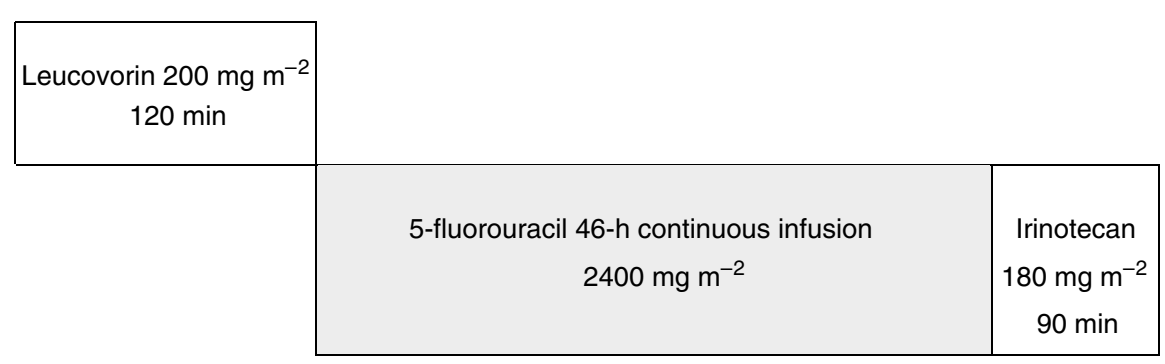

FOLFIRI-2: Irinotecan on day 3 at the end of 5FU infusion, plus hydroxyurea given the day before, day 1 and day 2 of each cycle.

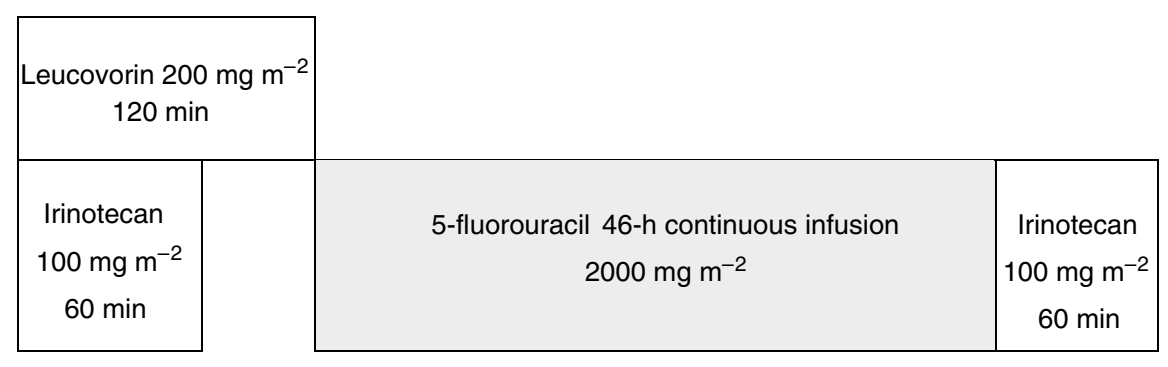

FOLFIRI-3: Double infusion of irinotecan before (day 1) and at the end of 5FU infusion (day 3).

Figure I Design of FOLFIRI (André et al, 1999), FOLFIRI-2 (Mabro et al, 2003) and FOLFIRI-3 regimens; cycles are repeated every 2 weeks. 
Blood tests and clinical evaluation were performed every 2 weeks, prior to treatment. Chemotherapy could be administered if neutrophil count was $\geqslant 1500 \mu \mathrm{l}^{-1}$, platelet count $\geqslant 100000 \mu \mathrm{l}^{-1}$ and if clinical toxicity was resolved or $<$ grade 2 . In case of grade $>2$ neutropenia, thrombocytopenia or diarrhoea toxicity, the dose of irinotecan was to be reduced from 100 to $80 \mathrm{mg} \mathrm{m}^{-2}$. If neutropenia, thrombocytopenia or diarrhoea $>$ grade 2 persisted at this latter dose, chemotherapy was discontinued.

\section{Supportive care}

Specific anti-emetic prophylaxis was left to the investigator's discretion. For patients who experienced an early cholinergic syndrome occurring during or shortly after irinotecan administration, atropine sulphate $(0.25 \mathrm{mg})$ could be given subcutaneously. The use of loperamide was recommended in case of diarrhoea.

\section{Study parameters}

Before each cycle, patients underwent a clinical examination, and blood cells were counted. All toxicities were reported according to the National Cancer Institute-Common Toxicity Criteria (NCICTC) (MacDonald et al, 1995). Carcinoembryogenic antigen, bilirubin, serum alkaline phosphatases, serum creatinine, lactate dehydrogenase, chest X-ray and CT scans were repeated every 8 weeks (i.e. every four cycles) or earlier in the case of worsening of clinical condition. Tumour response was assessed by RECIST criteria (Therasse et al, 2000). Tumour growth control was defined by the proportion of patients with response rate or stable disease.

\section{Statistical considerations}

Based on previous studies, we expected FOLFIRI-3 to achieve a $40 \%$ rate of nonprogressive patients at 6 months. According to a binomial distribution point estimate of proportion, with $5 \%$ significance and $80 \%$ power, 65 patients were to be enrolled. Survival times were calculated from the start of FOLFIRI-3 until death. Time to progression was calculated from the first day of FOLFIRI-3 to the date of progression for all the patients entering the study. Survival curves were obtained using the Kaplan-Meier method (Kaplan and Meier, 1958).

\section{RESULTS}

From 17 June 2001 to 19 December 2002, 65 patients were recruited from nine French institutions. Their characteristics are described in Table 1. All patients had previously been treated with a FOLFOX regimen (combination of oxaliplatin, infusion $5 \mathrm{FU}$ and LV), and had experienced disease progression while on FOLFOX (36 patients) or after discontinuation (29 patients). Thirteen patients $(20 \%)$ had previously been treated with at least two regimens for metastatic purpose before entering the FOLFIRI-3 study.

\section{Treatment}

The median number of treatment cycles administered was 7 (range, 1-20). Six patients (9\%) refused to continue after the first or the second course (personal convenience without toxicity $>$ grade 2). In six patients (9\%) treatment was stopped because of grade 3 or 4 toxicity. Tumour response was not assessable in nine of those 12 patients. In 39 patients $(60 \%)$ treatment was stopped because of disease progression after a median of eight courses. In 14 additional patients $(21 \%)$ chemotherapy was interrupted by investigator after 8-20 cycles, without evidence of disease progression nor severe toxicity.

Dose reductions occurred in 25 patients due to grade 3 toxicities, mainly vomiting, diarrhoea or mucositis. Irinotecan
Table I Patient characteristics $(n=65)$

\begin{tabular}{|c|c|c|}
\hline & $N$ & $\%$ \\
\hline \multicolumn{3}{|c|}{ Median age: 60 years (range: $30-79$ ) } \\
\hline \multicolumn{3}{|l|}{ Gender } \\
\hline Male & 32 & 49 \\
\hline Female & 33 & 51 \\
\hline \multicolumn{3}{|l|}{ WHO performance status } \\
\hline 0 & 32 & 49 \\
\hline 1 & 22 & 34 \\
\hline 2 & 11 & 17 \\
\hline \multicolumn{3}{|l|}{ Primary tumour } \\
\hline Colon & 49 & 75 \\
\hline Rectum & 16 & 25 \\
\hline \multicolumn{3}{|l|}{ Site of metastases } \\
\hline Liver & 52 & 80 \\
\hline Lung & 23 & 35 \\
\hline Peritoneum & 9 & 14 \\
\hline Nodes & I1 & 17 \\
\hline Other & 6 & 9 \\
\hline \multicolumn{3}{|l|}{ Involved sites } \\
\hline I & 36 & 55 \\
\hline 2 & 23 & 35 \\
\hline$>2$ & 6 & 9 \\
\hline Prior adjuvant chemotherapy: & 13 & 20 \\
\hline LV5FU & | | & 17 \\
\hline FOLFOX & 2 & 3 \\
\hline \multicolumn{3}{|c|}{ Number of lines for metastatic purpose received before FOLFIRI-3 } \\
\hline I line only & 52 & 80 \\
\hline 2 lines or more & 13 & 20 \\
\hline \multicolumn{3}{|c|}{ FOLFOX regimen received before FOLFIRI-3 } \\
\hline FOLFOX7 & 27 & 42 \\
\hline FOLFOX6 & 13 & 20 \\
\hline FOLFOX4 & 25 & 38 \\
\hline
\end{tabular}

dose was increased according to the design of the study only in 12 patients with a median dose level of $120 \mathrm{mg} \mathrm{m}^{-2}$ on days 1 and 3 . Grade 3 toxicity occurred only in one of these patients.

\section{Safety}

Side effects were collected for 463 cycles according to the NCI-CTC grade scale. Toxicities are listed in Table 2. Neutropenia reached grade $3 / 4$ in $37 \%$ of patients, including three patients $(5 \%)$ who had one episode of febrile neutropenia. There was one toxic death after the first course of chemotherapy related to a sepsis shock with neutropenia and diarrhoea. Overall, 10 patients (15\%) experienced at least one grade 4 toxicity and 20 patients $(31 \%)$ experienced one grade 3 nonhematological toxicity.

\section{Survival and objective response}

Progression free survival for 6 months was $42 \%$. From the start of FOLFIRI-3, median progression-free survival was 20.5 weeks $(4.7$ months) and median survival was 46 weeks (10.5 months). Survival curves are shown in Figure 2.

Tumour response was assessable in 56 patients and not assessable in nine patients (14\%). Response rates were calculated in the intent-to-treat population. Objective response was obtained in 15 patients ( 1 complete, 14 partial), achieving a $23 \%$ (95\% CI $13-33 \%$ ) response rate (15 out of 65 ). The number of responder 
Table 2 Toxicity of FOLFIRI-3 according to NCl-CTC grading (maximal grade per patient, collected from 463 cycles, 65 patients)

\begin{tabular}{lcccc}
\hline & \multicolumn{4}{c}{ NCI-CTC grade (\% of patients) } \\
\cline { 2 - 5 } & $\mathbf{I}$ & $\mathbf{2}$ & $\mathbf{3}$ & $\mathbf{4}$ \\
\hline Nonhaematological toxicities & & & & \\
$\quad$ Nausea & 28 & 29 & 9 & 0 \\
$\quad$ Vomiting & 12 & 19 & 8 & 0 \\
Mucositis & 20 & 19 & 5 & 2 \\
$\quad$ Diarrhoea & 25 & 38 & 22 & 1 \\
Asthenia & 28 & 20 & 11 & 3 \\
Hand-foot syndrome & 23 & 2 & 0 & - \\
Alopecia & 23 & 54 & - & - \\
Haematological toxicities & & & & \\
$\quad$ Neutropenia & 14 & 28 & 26 & 11 \\
$\quad$ Febrile neutropenia & - & - & 2 & 3 \\
$\quad$ Anaemia & 54 & 26 & 2 & 2 \\
$\quad$ Thrombocytopenia & 34 & 5 & 3 & 0 \\
\hline
\end{tabular}

NCI-CTC, National Cancer Institute-Common Toxicity Criteria.

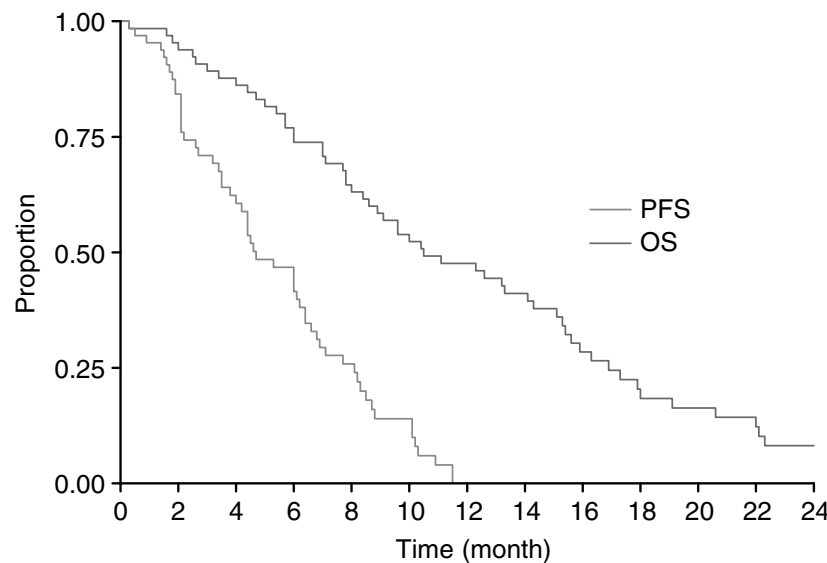

Figure 2 Progression-free survival and overall survival in the FOLFIRI-3 study (65 patients).

patients assessed by RECIST criteria are listed in Table 3. Disease was stable in 24 patients (37\%) and progressed in $17(26 \%)$. Tumour growth control was $60 \%$ (95\% CI $48-72 \%$ ).

Regarding assessable patients, response rate was $27 \%$ (95\% CI $15-39 \%$ ), and $22 \%$ in the subset of patients in whom disease progressed while on previous FOLFOX regimen, and $33 \%$ in the subset of patients in whom disease progressed after FOLFOX discontinuation.

\section{DISCUSSION}

This multicentre phase II study assessed the efficacy and tolerability of the FOLFIRI-3 regimen, a new combination of irinotecan and LV5FU, in patients with metastatic colorectal cancer previously treated with FOLFOX. With $42 \%$ of patients free of progression at 6 months, the main objective of the study was reached.

Several phase II studies (Pitot et al, 1997; Rougier et al, 1997; Rothenberg et al, 1999; Van Cutsem et al, 1999) and two large phase III studies (Cunningham et al, 1998; Rougier et al, 1998) established the efficacy of irinotecan after 5FU failure (Table 4). In
Table 3 RECIST number of the responder patients

\begin{tabular}{lcccc}
\hline Patient no. & Response & $\begin{array}{c}\text { RECIST at } \\
\text { baseline }\end{array}$ & $\begin{array}{c}\text { RECIST at } \\
\text { first } \\
\text { evaluation }\end{array}$ & $\begin{array}{c}\text { RECIST at } \\
\text { second } \\
\text { evaluation }\end{array}$ \\
\hline 103 & PR & 38 & 18 & 20 \\
105 & PR & 10 & 6 & 3 \\
108 & PR & 275 & 230 & 175 \\
112 & PR & 114 & 45 & 50 \\
113 & PR & 102 & 81 & 25 \\
202 & PR & 90 & 90 & 65 \\
212 & PR & 78 & 48 & 55 \\
205 & PR & 20 & 10 & 10 \\
301 & PR & 74 & 48 & 91 \\
306 & PR & 80 & 70 & 44 \\
308 & PR & 180 & 160 & 118 \\
501 & PR & 100 & 90 & 70 \\
505 & PR & 50 & 21 & 19 \\
803 & PR & 131 & 90 & 78 \\
404 & CR & 85 & 35 & 0 \\
\hline
\end{tabular}

RECIST, Response Evaluation Criteria in Solid Tumors.

phase II studies of irinotecan alone, after 5FU failure response rates were 11-16\% (Rougier et al, 1997; Rothenberg et al, 1999; Van Cutsem et al, 1999), and progression-free survival was 3-4 months (Pitot et al, 1997; Rougier et al, 1997; Rothenberg et al, 1999; Van Cutsem et al, 1999). In phase III studies of irinotecan after 5FU failure, progression-free survival was 3-4 months (Cunningham et al, 1998; Rougier et al, 1998; Fuchs et al, 2003). Response rate was reported in only one of those studies and was $4.5 \%$ (Rougier et al, 1998).

The combination of irinotecan with $5 \mathrm{FU}$ and LV after 5FU failure was evaluated in three phase II studies. Reported response rates were 11.4-21\% (Ducreux et al, 1999; Gil-Delgado et al, 2001; Rougier et al, 2002). As shown in Table 4, results observed with regimens combining irinotecan, $5 \mathrm{FU}$ and $\mathrm{LV}$ after $5 \mathrm{FU}$ failure seem slightly better than those with irinotecan alone, in a cross-study comparison. More recently, a large randomised phase III study was conducted enrolling more than 2000 patients. In this study, the addition of irinotecan to 5FU after 5FU failure achieved better survival (14.8 vs 13.9 months from the start of front-line 5FU) and higher response rate $(21 v s 11 \%)$ than irinotecan alone after $5 \mathrm{FU}$ failure (Seymour et al, 2005). These results encourage the administration of $5 \mathrm{FU}$ with irinotecan despite previous 5FU failure.

Efficacy of irinotecan in patients previously treated with FOLFOX is less documented. Results of the FOLFIRI, FOLFIRI-2 and FOLFIRI-3 studies are summarised in Table 4 . In a randomised trial recently reported, irinotecan alone achieved a $4 \%$ response rate and 2.7 progression-free survival in 94 patients previously treated with $5 \mathrm{FU}$ as front line and FOLFOX4 as second line (Rowland et al, 2005).

In the present study, the progression-free survival was 4.7 months and the intent-to-treat response rate was $23 \%$, higher than those reported with irinotecan alone, FOLFIRI and FOLFIRI-2 after FOLFOX. In a cross-study comparison, efficacy of FOLFIRI-3 seems slightly better than FOLFIRI-2, as FOLFIRI-2 showed a high toxicity profile. The main FOLFIRI-2 grade 3-4 toxicities were diarrhoea (31\%), neutropenia (52\%), and febrile neutropenia (14\%) (Mabro et al, 2003). Toxicity of FOLFIRI-3 was moderate, lower than FOLFIRI-2 study and quite higher than FOLFIRI in pretreated patients (Andre et al, 1999). It is difficult to assess if this increased toxicity is related to the divided dose of irinotecan or to the total dose of irinotecan, which is $10 \%$ more than in the FOLFIRI (200 instead of $180 \mathrm{mg} \mathrm{m}^{-2}$ per cycle). Differences should be also partly due to the subset of patients. In particular, patients 
Results of main published phase II and III studies of irinotecan in previously treated patients with metastatic colorectal cancer

\begin{tabular}{|c|c|c|c|c|}
\hline Reference & Study phase & $\mathbf{N}$ & Response rate (\%) & Progression-free survival (months) \\
\hline \multicolumn{5}{|l|}{ Irinotecan alone after 5FU } \\
\hline Van Cutsem et al, 1999 & $\|$ & 107 & 13.7 & 4 \\
\hline Pitot et al, 1997 & $\|$ & 90 & 13.3 & - \\
\hline Rothenberg et al, 1999 & $\|$ & 166 & 11 & - \\
\hline Rougier et al, 1997 & $\|$ & 140 & 16 & - \\
\hline Cunningham et al, 1998 & III & 189 & - & - \\
\hline Rougier et al, 1998 & III & 133 & 5 & 4.2 \\
\hline Fuchs et al, 2003 & III & 291 & - & 3.5 \\
\hline \multicolumn{5}{|c|}{ Irinotecan combined with LV5FU after 5FU } \\
\hline Ducreux et al, 1999 & $\|$ & 55 & 22 & 6.3 \\
\hline Gil-Delgado et al, 200। & $\|$ & 39 & 21 & - \\
\hline Rougier et al, 2002 & Randomised phase II & 101 & 11.4 & - \\
\hline \multicolumn{5}{|c|}{ Irinotecan combined with LV5FU after FOLFOX } \\
\hline André et al, 1999 & $\|$ & 33 & 5.5 & 4.1 \\
\hline Tournigand et al, 2004 & III & 66 & 4 & 2.5 \\
\hline Mabro et al, 2003 & $\|$ & 29 & 17 & 4 \\
\hline Maindrault et al, 2002 & $\|$ & 20 & 20 & 6.7 \\
\hline FOLFIRI-3 & $\|$ & 65 & 23 & 4.7 \\
\hline
\end{tabular}

of the FOLFIRI-3 study were less selected and $17 \%$ entered the study with a PS 2 .

In conclusion, FOLFIRI-3 is a feasible regimen with encouraging response rate and progression-free survival in patients

\section{REFERENCES}

André T, Louvet C, Maindrault-Goebel F, Couteau C, Mabro M, Lotz JP, Gilles-Amar V, Krulik M, Carola E, Izrael V, de Gramont A (1999) CPT11 (irinotecan) addition to bimonthly, high-dose leucovorin and continuous-infusion 5-fluorouracil (FOLFIRI) for pretreated metastatic colorectal cancer. Eur J Cancer 35: $1343-1347$

Cunningham D, Pyrhönen S, James RD, Punt CJ, Hickish TF, Heikkila R, Johannesen TB, Starkhammar H, Topham CA, Awad L, Jacques C, Herait P (1998) Randomised trial of irinotecan plus supportive care $v s$ supportive care alone after fluorouracil failure for patients with metastatic colorectal cancer. Lancet 352: 1413-1418

de Gramont A, Figer A, Seymour M, Homerin M, Hmissi A, Cassidy J, Boni C, Cortes-Funes H, Cervantes A, Freyer G, Papamichael D, Le Bail N, Louvet C, Hendler D, de Braud F, Wilson C, Morvan F, Bonetti A (2000) Leucovorin and fluorouracil with or without oxaliplatin as first-line treatment in advanced colorectal cancer. J Clin Oncol 18: 2938-2947

Douillard JY, Cunningham D, Roth AD, Navarro M, James RD, Karasek P, Jandik P, Iveson T, Carmichael J, Alakl M, Gruia G, Awad L, Rougier P (2000) Irinotecan combined with fluorouracil compared with fluorouracil alone as first-line treatment for metastatic colorectal cancer: a multicentre randomised trial. Lancet 355: $1041-1047$

Ducreux M, Ychou M, Seitz JF, Bonnay M, Bexon A, Armand JP, Mahjoubi M, Mery-Mignard D, Rougier P (1999) Irinotecan combined with bolus fluorouracil, continuous infusion fluorouracil, and high-dose leucovorin every two weeks (LV5FU2 regimen): a clinical dose finding and pharmacokinetic study in patients with pretreated metastatic colorectal cancer. J Clin Oncol 17: 2901-2908

Falcone A, di Paolo A, Masi G, Allegrini G, Danesi R, Lencioni M, Pfanner E, Comis S, Del Tacca M, Conte P (2001) Sequence effect of irinotecan on pharmacokinetics and toxicity in chemotherapy-naive metastatic colorectal cancer patients. J Clin Oncol 19: 3456-3462

Fuchs CS, Moore MR, Harker G, Villa L, Rinaldi D, Hecht J (2003) Phase III comparison of two irinotecan dosing regimens in second-line therapy of metastatic colorectal cancer. J Clin Oncol 21: 807-814

Gil-Delgado MA, Guinet F, Castaing D, Adam R, Coeffic D, Durrani AK, Bismuth H, Khayat D (2001) Prospective phase II trial of irinotecan, 5fluorouacil, and leucovorin in combination as salvage therapy for advanced colorectal cancer. Am J Clin Oncol 24: 101-105 previously treated with FOLFOX. Future studies should evaluate the combination of FOLFIRI-3 with molecular targeted therapies like bevacizumab, cetuximab or new oral anti-REGF molecules.
Goldberg RM, Sargent DJ, Morton RF, Fuchs CS, Ramanathan RK, Williamson SK, Findlay BP, Pitot HC, Alberts SR (2004) A randomised controlled trial of fluorouracil plus leucovorin, irinotecan, and oxaliplatin combinations in patients with previously untreated metastatic colorectal cancer. J Clin Oncol 22: 4-6

Grothey A, Deschler B, Kroening H, Ridwelski K, Reichardt P, Kretzschmar A, Clemens M, Hirschmann W, Lorenz M, Asperger W, Buechele T, Schmoll HJ (2002) Phase III study of bolus 5-fluorouracil (5FU)/folinic acid (FA) (Mayo) vs weekly high-dose $24 \mathrm{~h} 5$-FU infusion/FA+oxaliplatin (OXA) in advanced colorectal cancer (ACRC). Proc Am Soc Clin Oncol (Orlando, FL, USA) 21: 129a (abstract)

Guichard S, Cussac D, Hennebelle I, Bugat R, Canal P (1997) Sequencedependent activity of the irinotecan-5FU combination in human coloncancer model HT-29 in vitro and in vivo. Int J Cancer 73: 729-734

Kaplan EL, Meier P (1958) Nonparametric estimation from incomplete observations. I Am Stat Assoc 53: 457-481

Mabro M, Louvet C, André T, Carola E, Gilles-Amar V, Artru P, Krulik M, de Gramont A, on behalf GERCOR (2003) Bimonthly leucovorin, infusion, 5-fluorouracil, hydroxyurea, and irinotecan (FOLFIRI-2) for pretreated metastatic colorectal cancer. Am J Clin Oncol 25: $254-258$

MacDonald J, Haller D, Mayer R (1995) Grading of toxicity. In: Manual of Oncologic Therapeutics, MacDonald J, Haller D, Mayer R (eds) pp 519523. Lippincott: Philadelphia

Maindrault F, Louvet C, Tournigand C, Gervais H, Mabro M, Artru P, Garcia ML, André T, Carola C, de Gramont A (2002) Leucovorin, 5fluorouracil infusion and irinotecan (FOLFIRI-3) in pretreated patients with metastatic colorectal cancer. Proc Am Soc Clin Oncol (Orlando, FL, USA) 21: 658a (abstract)

Mans DRA, Grivicich I, Peters GJ, Schwartsmann G (1999) Sequencedependent growth inhibition and DNA damage by the irinotecan-5fluorouracil combination in human colon carcinoma cell lines. Eur J Cancer 35: $1851-1861$

Mullany S, Svingen PA, Kaufmann SH, Erlichman C (1998) Effect of adding the topoisomerase I poison 7-ethyl 10-hydroxycamptothecin (SN 38) to 5-fluorouracil and folinic acid in HCT8 cells: elevated dTTP pools and enhanced cytotoxicity. Cancer Chemother Pharm 42: 391-399 
Pitot HC, Wender DB, O'Connell MJ, Schroeder G, Goldberg RM, Rubin J, Mailliard JA, Knost JA, Ghosh C, Kirschling RJ, Levitt R, Windschitl HE (1997) Phase II trial of irinotecan in patients with metastatic colorectal carcinoma. J Clin Oncol 15: 2910-2919

Rothenberg ML, Cox JV, DeVore RF, Hainsworth JD, Pazdur R, Rivkin SE, Macdonald JS, Geyer Jr CE, Sandbach J, Wolf DL, Mohrland JS, Elfring GL, Miller LL, Von Hoff DD (1999) A multicenter, phase II trial of weekly irinotecan (CPT-11) in patients with previously treated colorectal carcinoma. Cancer 85: 786-795

Rougier P, Bugat R, Douillard JY, Culine S, Suc E, Brunet P, Becouarn Y, Ychou M, Marty M, Extra JM, Bonneterre J, Adenis A, Seitz JF, Ganem G, Namer M, Conroy T, Negrier S, Merrouche Y, Burki F, Mousseau M, Herait P, Mahjoubi M (1997) Phase II study of irinotecan in the treatment of advanced colorectal cancer in chemotherapy naive patients and patients pretreated with fluorouracil based chemotherapy. J Clin Oncol 15: 251-260

Rougier P, Lepille D, Bennouna J, Marre A, Ducreux M, Mignot L, Hua A, Mery-Mignard D (2002) Antitumour activity of three second-line treatment combinations in patients with metastatic colorectal cancer after optimal 5-FU regimen failure: a randomised, multicentre phase II study. Ann Oncol 13: 1558-1567

Rougier P, Van Cutsem E, Bajetta E, Niederle N, Possinger K, Labianca R, Navarro M, Morant R, Bleiberg H, Wils J, Awad L, Herait P, Jacques C (1998) Randomised trial of irinotecan $v s$ fluorouracil by continuous infusion after fluorouracil failure in patients with metastatic colorectal cancer. Lancet 352: $1407-1412$

Rowland KM, Pitot HC, Sargent DJ, Philip PA, Mitchell EP, Mailliard JA, Goldberg RM, Alberts SR (2005) Results of third line therapy on N9841: a randomized phase III trial of oxaliplatin/5-fluorouracil/leucovorin (FOLFOX4) vs irinotecan (CPT-11) in patients with advanced colorectal cancer previously treated with prior 5FU chemotherapy. Proc Am Soc Clin Oncol (Orlando, FL, USA) 24: 3519a (abstract)

Saltz LB, Cox JV, Blanke C, Rosen LS, Fehrenbacher L, Moore MJ, Maroun JA, Ackland SP, Locker PK, Pirotta N, Elfring GL, Miller LL (2000) Irinotecan plus fluorouracil and leucovorin for metastatic colorectal cancer. Irinotecan study group. $N$ Engl J Med 343: 905-914

Seymour MT, for the UK NCRI Colorectal Clinical Studies Group and FOCUS Trial Investigators (2005) Fluorouracil, oxaliplatin and CPT-11 (irinotecan), use and sequencing (MRC FOCUS): a 2135-patient randomized trial in advanced colorectal cancer (ACRC). Proc Am Soc Clin Oncol (Orlando, FL, USA) 24: 3518a (abstract)

Therasse P, Arbuck SG, Eisenhauer EA, Wanders J, Kaplan RS, Rubinstein L, Verweij J, Van Glabbeke M, van Oosterom AT, Christian MC, Gwyther SG (2000) New guidelines to establish response to treatment in solid tumors. J Nat Cancer Inst 92: 205-216

Tournigand C, André T, Achille E, Lledo G, Flesh M, Mery-Mignard D, Quinaux E, Couteau C, Buyse M, Ganem G, Landi B, Colin P, Louvet C de Gramont A (2004) FOLFIRI followed by FOLFOX6 or the reverse sequence in advanced colorectal cancer: a randomized GERCOR study. J Clin Oncol 22: 229-237

Van Cutsem E, Cunningham D, Ten Bokkel Huinink WW, Punt CJ, Alexopoulos CG, Dirix L, Symann M, Blijham GH, Cholet P, Fillet G, Van Groeningen C, Vannetzel JM, Levi F, Panagos G, Unger C, Wils J, Cote C, Blanc C, Herait P, Bleiberg H (1999) Clinical activity and benefit of irinotecan (CPT-11) in patients with colorectal cancer truly resistant to 5-fluorouracil (5-FU). Eur J Cancer 35: 54-59 